\title{
Prevalence and risk factors associated with downer cow syndrome at smallholders dairy farms in Middle Egypt
}

\author{
Noha A. Beder ${ }^{1}$, Besheer G. Elshafey ${ }^{1}$, Sabry A. El-Khodery², Mohamed Y. Nasr ${ }^{1}$
}

${ }^{1}$ Department of Animal Medicine, Faculty of Veterinary Medicine, Damanhour University, Damanhour 22511, Egypt.

${ }^{2}$ Department of Internal Medicine and Infectious Diseases, Faculty of Veterinary Medicine, Mansoura University, Mansoura 35516, Egypt

\section{ARTICLE HISTORY}

Received: 14.09 .2020

Revised: 11.12 .2020

Accepted: 12.12 .2020

Address correspondence to Noha A. Beder; Tel: +2-045-3907212, Fax: 0453320570;

E-mail:

noha.abdallah@vetmed.dmu.edu.eg; ORCID: 0000-0001-5517-1761

\section{ABSTRACT}

\begin{abstract}
Objective: This study was conducted to determine the prevalence and risk factors associated with downer cow syndrome (DCS) in Middle Egypt.

Design: Case-control study

Animals: A total of 1,300 cross breeding Holestein dairy cattle in 30 small scale farms were involved in the study during the period from September 2018 to August 2019.

Procedures: Three hundred and twenty downers $(24.6 \%)$ were investigated and were subject to clinical examination. A questioner to farm owners was designed focusing on risk factors for occurrence of downers.

Results: The prevalence of downers due to metabolic, digestive, infectious, musculoskeletal and nerve injuries was $8.1 \%, 6.9 \%, 5.4 \%, 2.3 \%$ and $1.9 \%$, respectively. Multivariate logistic regression analysis showed that conventional ration (OR: $2.8, \mathrm{Cl} 95 \%$ : 4.3-6.2), indoor housing (OR 3.4, CI 95\% 2.1-3.7), inadequate hygienic measures (OR: 2.05, $\mathrm{Cl}$ 95\%: 4.55-6.5), concrete flooring (OR: 3.89, Cl 95\%: 1.4-10.9), > 20 kg daily milk yield (DMY) (OR: 3.037, Cl 95\%: 1.46-6.34), poor body condition score (BCS) (OR: 20.6, Cl 95\%: 6.6-6.9), older age (OR: 1.05, Cl 95\%: 1.05-2.20), first 45 days in milk (DIM) (OR: $12.4, \mathrm{Cl}$ 95\%: 3.3-4.3), and winter (OR: 1.47, Cl 95\%: 0.16-1.36) were potential risk factors. DCS showed an association with hyperthermia $(P<0.01)$, tachycardia $(P<0.01)$, polypnea $(P<0.01)$, ruminal hypomotility $(P<0.01)$ and inappetence $(P<0.01)$.

Conclusion and Clinical relevance: The present results indicate that DCS is a prevalent issue at smallholders dairy farms. It is mainly due to metabolic causes. Appropriate control strategies are recommended, focusing mainly on the potential risk factors identified in this study.
\end{abstract}

Keywords: DCS, Prevalence, Risk factors, Middle Egypt.

\section{INTRODUCTION}

Downer cow syndrome is one of the most common and costly diseases that occurs in lactating dairy animals during peripartum period, causing severe economic losses in terms of heavy reduction in milk yield and impaired reproductive performance [1]. It was defined as alert cow that could not stand up for 12 hours or more [2]. Other definitions include all non-ambulatory cattle (alert or non-alert) that are unable to stand for any duration of time without assistance [3].

Hypocalcaemia is an emerging metabolic disorder that occurs during the transition period and is likely to occur with other health problems [4]. It's the most common cause of downer cow syndrome [5] that can also be caused by injuries, muscle damage, mineral deficiency, toxic mastitis, or metritis [6]. The periparturient period in cattle refers to the 2-3 weeks pre-partum and post-partum period and is a transitional phase marked by changes in the endocrine status of the animal for the supply of lacto-genesis and parturition. It is also characterized by changes in metabolism, nutrient utilization and disruption of immune system function. These changes constitute a risk factor for the development of DCS [7]. Total mixed ration, an average milk production of more than $9090 \mathrm{~kg} / \mathrm{cow} /$ year, and herd size of more than 100 cows increased the risk of having a downer cow [3]. A marked decrease in plasma electrolyte concentrations was shown to increase the risk of developing DCS [8]. Cattle with extreme acidosis can also progress to include depression, dehydration, toxaemia and DCS [9]. Most studies on periparturient conditions are focused on intensively managed large dairy herds [10]. However, there is little documentation on these conditions at the smallholder dairy production system. Therefore, the aim of this study was to evaluate the prevalence of downer cow syndrome in Egyptian small-scale dairy farms and its associated risk factors.

\section{MATERIALS AND METHODS}

\subsection{Farms and data collection}

A total of 1300 cross breeds Holestein dairy cattle in 30 small-scale dairy farms (30-50 animals) were followed up 
during the period from September, 2018 to August, 2019 for detection of downer cases in Middle Egypt. A total of 320 downer cows that didn't respond to primary treatments within the first 48 hours of recumbency were recorded. These animals were recumbent for 2-5 days at time of examination. A structured questioner to farm owners was constructed focusing on risk factors for DCS. Risk factors including feeding type, housing system model, floor type, mineral supplementation, and application of proper hygienic measures were recorded at the farm level. While the risk factors at the animal level were age, BCS, DIM, DMY and the history of previous recumbency episodes. Moreover, Season was recorded as an environmental factor.

\subsection{Clinical examinations}

All downer cows were subjected to thorough clinical examination including rectal temperature, ruminal movements, respiratory and heart rates, and BCS determination according to Constable et al. [11]. Complete history was gathered from the owners regarding appetite, falling and slippering. Musculoskeletal examinations were performed on each cow according to Poulton et al. [12] for assessment of limb and the spinal column fracture and damage of joints, tendons, ligaments, and muscles. Examination of udder and uterus was also performed for detection any pathological changes (mastitis and/or metritis).

\subsection{Statistical analysis}

Analysis of risk factors potentially associated with the occurrence of downer cow syndrome was evaluated in two steps using logistic regression. In the first step, we conducted a univariate analysis of each hypothesized risk factor (independent variables) and selected those variables with $\mathrm{P}<$ 0.25 for further multivariable logistic regression analysis. The fitness of the model was assessed using the Hosmer and Lemeshow's goodness of fit. Spearman's correlation test was used to check the correlation among the independent variables. The results were each expressed as a $\mathrm{P}$ value and odds ratio (OR) with a 95\% confidence interval (CI 95\%). A chi square $(\chi 2)$ analysis test was used to study the possible association between DCS and the clinical findings variables. All statistical analyses were performed using SPSS ver. 20.0, USA.

\section{RESULTS}

Based on our results from field clinical examinations in conjunction with detailed histories from farmers and guidance veterinarians, recumbent cows were categorized into classes of metabolic, digestive, infectious, musculoskeletal and neurological disorders. The downer cows, due to metabolic causes, were alert, bright and unable to stand on their feet. The investigated digestive disorders were ruminal acidosis, vagal indigestion, abomasal displacement and impaction and diarrhea. Infectious causes included acute mastitis, metritis and ephemeral fever. The musculoskeletal disorders included hip dislocation, myopathy and bone fractures. The category of nerve injury included nerve paralysis and paresis that did not originate from the central nervous system.
The prevalence of downer cow syndrome in small-scale dairy farms in Middle Egypt was $24.6 \%$. In addition, the prevalence of downers due to metabolic, digestive, infectious, musculoskeletal and nerve injuries was $8.1 \%, 6.9$ $\%, 5.4 \%, 2.3 \%$ and $1.9 \%$, respectively.

Regarding the risk factor analysis, feeding type, housing system, mineral supplementation, proper hygienic measures, floor type, DIM, age, BCS, DMY and season were all significant on the univariate analyses $(p<0.25)$ and subjected to multivariate logistic regression analyses (Table 1 ). The potential risk factors identified in multivariate analyses were summarized in Table 2 . The final model had a good fit (Hosmer and Lemeshow test: $\chi 2=6,676, P=0.572$ ). At the farm level, there was a significant association between the feeding type and the DCS in which cows fed conventional rations were at high risk ( $P<0.01$; OR: 2.8; $\mathrm{Cl} 95 \%$ 4.3-6.2) and the highest rate $(25.6 \%)$ compared to those fed a total mixed ration (TMR). The indoor housing system has also been identified as a potential risk factor for DCS (P < 0.01; OR: 3.4; $\mathrm{Cl} 95 \% 2.1-3.7)$. Indoor cows were more affected (30\%) than those with semi-open system (14.8\%). In regards, cows not applying proper hygienic measures were at higher risk of developing DCS ( $\mathrm{P}<0.01$; OR: 2.05; Cl $95 \%$ : 4.55-6.5), respectively. In addition, the farms with a concrete floor had a significant association ( $P<0.01$; OR: 3.89; Cl $95 \%$ : 1.4-10.9) with the syndrome occurrence.

Cows housed in farms with concrete floors were more affected (26.2 \%) than those housed in farms with earth floor (21\%). At the animal level, DMY was found to have a significant effect on the prevalence of the syndrome where cows with a milk yield of more than $20 \mathrm{~kg}$ per day $(P<0.01$; OR: 3.037, $\mathrm{Cl} 95 \%$ : 1.46-6.34) had the highest occurrence (35.6\%).

BCS also had a significant effect on the prevalence of DCS where cows with poor BCS were at high risk of being downer ( $P$ < 0.01; OR: 20.6; Cl $95 \%$ : 6.6-6.9) than those with good and medium BCS with the highest occurrence (76.1\%). Furthermore, There was a significant association between age of cows and high prevalence of DCS where the older cows $>7$ years ( $43 \%$ ) were more likely to be associated with the incidence ( $P<0$. 01; OR: 1.05; CI 95\%: 1.05-2.20). DIM had a significant effect on the occurrence of downer cases, as the cows in milk for the first 45 days was significantly associated ( $\mathrm{P}<0.01$; OR: 12.4; $\mathrm{Cl} 95 \%$ : 3.3-4.3) with the syndrome occurrence with the highest incidence rate (66.7\%). Season has also been found to affect the prevalence of the syndrome, as winter $(\mathrm{P}<0.01$; OR: $1.47, \mathrm{Cl} 95 \%$ : 0.16-1.36) had the highest incidence rate $(7.1 \%)$ while summer had the lowest rate $(5.3 \%)$.

Statistical analysis of the clinical findings revealed that there was a significant association between DCS and hyperthermia $(P<0.01)$ in which $35(10.9 \%)$ of the downers were affected by an increase in body temperature (39.2-39.9 $\left.{ }^{\circ} \mathrm{C}\right)$. Also, there was a significant association between the occurrence of downer cows and tachycardia $(P<0.01)$ in which $40(12.5 \%)$ of downer cows were affected by an increase in heart rate ( $80-88$ beats / minute). There was also 
a significant association between the syndrome and polypnea $(P<0.01) ; 47$ (14.69\%) of the downer cows had an increased respiratory rate (30-35 breaths / minute). Ruminal hypomotility (1-2 contractions/2 minutes) was significantly associated with downer cows ( $P<0.01) ; 285$ (89\%) had ruminal hypomotility. In addition, there was a significant association between the presence of the downer cow and the appetite $(P<0.01)$ in which $297(92.8 \%)$ of the cases suffered from inappetence.

Table 1. Univariate analysis of risk factors associated with occurrence of downer cow syndrome (DCS) in small-scale dairy farms in Middle Egypt.

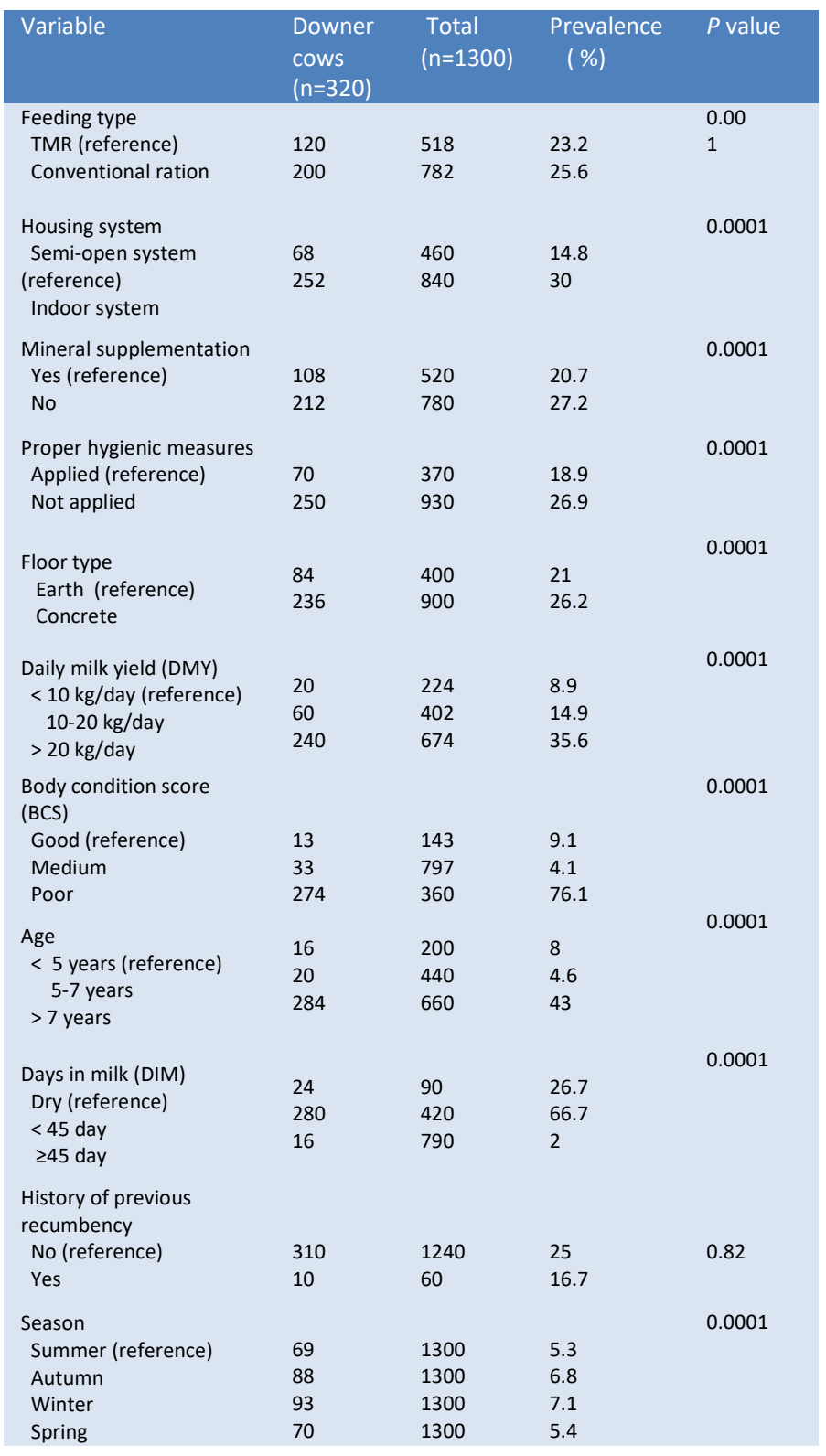

\section{DISCUSSION}

This study aimed to explain the prevalence and risk factors of downer cows in small-scale dairy farms in Middle Egypt. The incidence of this problem among the investigated dairy cows was $24.60 \%$, which was found to be higher than that recorded by Cox et al. [13] (21.4\%), Abuom et al. [14] (12.6 $\%)$, Rulff et al. [15] (2-15\%) and Duraj and Ceroni [16] (4.89 $\%)$. This variation in the prevalence rate may be due to housing, feeding, hygienic practices and other contributing factors. Metabolic, infectious, musculoskeletal, and nerve disorders are the main causes of downer cases [17]. The present study showed the highest prevalence of metabolic disorders. This finding is similar to that recorded by Shpiegel et al. [18]. Hypocalcemia [19] and hypophosphatemia [20] are the most common causes of DCS. On the other hand, Labonte et al. [21] recorded the musculoskeletal causes. Downer cows of metabolic causes were alert, bright, tried to stand up repeatedly but failed to lift their feet, as previously stated by Kachhawaha and Tanwar [22]. Feeding type, housing system, mineral supplementation, hygienic measures, floor type, DMY, BCS, age, DIM and season were the potential risk factors identified in this study by final multivariate logistic regression analysis for downer cow occurrence. Feeding type was found to have a significant impact on the prevalence of downer cases. The prevalence of cows fed conventional rations was higher than those fed TMR. This finding is confirmed by Wubishet et al. [23] who concluded that dietary deficiencies as a result of poor ration formulation is the most probable cause of metabolic disorders increasing the risk of downer syndrome occurrence. In regard to the housing system, the indoor housing system increased the risk of DCS incidence compared to semi-open system. Poor exposure to adequate sunlight and subsequent improper vitamin $D$ production increased the risk of developing hypocalcaemia, which is the main cause of DCS [4]. In addition, the prevalence of downer cases in this study was significantly associated with hygienic measures. Cows housed in farms with insufficient hygienic measures had higher prevalence than those with proper hygienic measures. The probability of health and performance problems increased by 5.1-fold when more than $50 \%$ of the lying areas were soiled with manure [24]. Insufficient cleaning or use of disinfectants could help to retain dirt and moistures increasing the risk of slipping, musculoskeletal injuries and mastitis.

Table 2. Multivariate logistic regression analysis of risk factors associated with the occurrence of downer cow syndrome (DCS) in small-scale dairy farms in Middle Egypt

\begin{tabular}{|c|c|c|c|c|}
\hline Variable & $\beta$ & OR & $\mathrm{Cl} 95 \%$ & P value \\
\hline Feeding type & 1.5 & 2.8 & $4.3-6.2$ & 0.0001 \\
\hline Housing system & 1.05 & 3.4 & 2.1- 3.7 & 0.0001 \\
\hline $\begin{array}{l}\text { Proper hygienic } \\
\text { measures }\end{array}$ & 4. 1 & 2.05 & $4.55-6.5$ & 0.0001 \\
\hline Floor type & 1.359 & 3.89 & $1.4-10.9$ & 0.0001 \\
\hline $\begin{array}{l}\text { Daily milk yield } \\
\text { (DMY) }\end{array}$ & 1.111 & 3.037 & $1.46-6.34$ & 0.007 \\
\hline $\begin{array}{l}\text { Body condition } \\
\text { score (BCS) }\end{array}$ & 3.03 & 20.6 & 6.6- 6.9 & 0.0001 \\
\hline Age & 2.91 & 1.05 & $1.05-2.20$ & 0.0001 \\
\hline $\begin{array}{l}\text { Days in milk } \\
\text { (DIM) }\end{array}$ & 2.5 & 12.4 & $3.3-4.3$ & 0.0001 \\
\hline Season & -0.76 & 1.47 & $0.16-1.36$ & 0.006 \\
\hline
\end{tabular}

$\beta$, regression coefficient; $\mathrm{Cl}$, confidence interval; $\mathrm{OR}$, odds ratio. 
Concerning the floor type, the rate of the syndrome significantly increased with cows housed in farms with concrete floors than in farms with earth floors. This may be due to high risk of physical injury of the musculoskeletal system in concrete floor [25]. Cows with milk yield of more than $20 \mathrm{~kg} /$ day were at the highest risk to be downers. Similar result was reported by Cox et al. [13] in Minnesota farms, who stated that the downer cows were $48 \%$ high producers, $46 \%$ average producers and only $6 \%$ low producers. Increased milk production during that time and subsequent demand for Ca often develop hypocalcaemia, increasing the probability of DCS occurrence [23]. Regarding to BCS, Cows with poor BCS significantly affect the incidence of downer cases. This result is supported by Green et al. [3] who recorded a recovery rate of $8.1 \%$ for downer cows with BCS below 2.5, while for cows with BCS below $2.75 \%$ or higher, it was $16.6 \%$. Cows with low score after parturition had a high risk of hypocalcemia [26], displaced abomasum, fatty liver, ketosis, dystocia and retained placenta [27]. On the contrary, Busato et al. [28] stated that Cows in good BCS were at higher risk of metabolic problems due to excessive mobilization of body reserves. Age was found to have a significant effect on the incidence of the syndrome; the highest prevalence was recorded in cows over 7 years of age. This finding coincided with that recorded by Bicalho et al. [29] and Duraj and Ceroni [16]. Cows in the first or second lactation have a very low risk of becoming recumbent around parturation [5]. Older cows are more likely to be recumbent due to hypocalcemia as a primary or contributing cause [11].

Cows at the first 45 days in milk were at the highest risk of developing downer syndrome. This result is confirmed by Labonte et al. [21] who recorded that $59 \%$ of downer cows were between 0 and 7 DIM, 14\% were between 8 and 60 DIM, $20 \%$ were $>60$ DIM and $7 \%$ were dry and this may be due to the high incidence of most post-partum diseases. Metabolic stress that occurs during this period as a part of the transition period leading to a high incidence of disorders; metabolic as milk fever; infectious as mastitis; and reproductive disorders as retained placenta $[7,30]$ increasing the risk of developing DCS.

Season significantly associated with the prevalence of downer cases in this study. Winter had the highest prevalence in accordance with that obtained by Cox et al. [13]. This may be due to winter is the season of calving and related disorders such as milk fever, digestive and reproductive disorders which increase the risk of DCS by fivefold [31]. In addition, farmers depend mainly on conventional forage-based diets during the winter season in Egypt.

Concerning to clinical findings, significant association between DCS and hyperthermia was found. This may be present in DCS-affected cows in regard to the primary cause of recumbency (i.e. acute mastitis or metritis). Also, DCS is significantly associated with tachycardia. Labonte et al. [21] recorded tachycardia as a common observation in downer cows and a significant association between high heart rate and negative outcome in DCS cases. Most conditions that cause DCS are associated with tachycardia. In addition, Hyperthermia, tachycardia and polypnea are non-specific indicators for pain. Also, there was a significant association between DCS and reduced appetite and decreased rumen contraction. This is mainly due to hypocalcemia [32]. The recorded polypnea may be due to the pressure of the abdominal contents on the diaphragm. Systemic effect of toxaemia in infectious disease and ruminal acidosis plays a vital role in the prevalence of investigated clinical findings.

More epidemiological studies on each categorical cause of DCS are required to better understand and control this syndrome. Also, the physical examination used in this study cannot be regarded as a gold standard for the establishment of a definitive diagnosis. In conclusion, the results of the present study indicate that DCS is widespread at small-scale dairy farms in Middle Egypt. Metabolic disorders had a major impact on the prevalence of DCS identified as a consequence of the highest incidence rate and associated risk factors. Recognizing potential risk factors associated with this syndrome would help to develop effective control strategies in Middle Egypt and other areas with the same farming practices to minimize economic losses.

\section{Acknowledgement}

We acknowledge the farmers for their willingness to participate and to provide information about their farms and animals.

\section{Conflict of interest}

\section{Authors declare that there is no conflict of interest}

\section{Animal Ethics Committee Permission}

The study procedures were carried out in accordance with the recommendations of the local ethics of the institutional Committee of Faculty of Veterinary Medicine, Damanhour University, Egypt (DMU/VetMed-2019-/0145).

\section{Authors' contribution}

B. E. performed the clinical study and drafted the manuscript, N.B. analyzed the data and revised the manuscript, M.N. and S.E. revised the manuscript.

\section{REFERENCES}

[1] Senthilkumar V, Mohamed Safiullah A, Kathiravan G, Subramanian M, Mani K. Economic Analysis of Metabolic Diseases in Bovines: A Review. IJAVST 2013; 2 (1): 64-71.

[2] Burton AJ, Nydam DV, Ollivett TL, et al. Prognostic indicators for nonambulatory cattle treated by use of a flotation tank system in a referral hospital: 51 cases (1997-2008). J Am Vet Med Assoc. 2009; 234:1177-1182. https://doi.org/10.2460/javma.234.9.1177

[3] Green AL, Lombard JE, et al. Factors associated with occurrence and recovery of non-ambulatory dairy cows in the United States. J. Dairy Sci 2008; 91: 2275-2283. https://doi.org/10.3168/jds.2007-0869

[4] Saed H, Ibrahim H, El-khodery S, Youssef M. Prevalence and potential risk factors of hypocalcaemia in dairy cows during transition period at Northern Egypt. Mans. Vet. Med. J 2020; 21: 21-30. https://doi.org/10.35943/mvmj.2020.21.104

[5] Gelfert CC, Alpers I, Dallmeyer M, Decker MA, Huting A, Lesch S, Baumgartner W, Staufenbiel R. Factors affecting the success rate of treatment of recumbent dairy cows suffering from hypocalcaemia. J Vet 
Med A 2007; 54: 191-198. https://doi.org/10.1111/j.14390442.2007.00940.x

[6] Gerlof BJ. Herd health. In: Radostits, O., Ed. Food Animal Production Medicine, 3rd ed., W.B. Saunders G, Philadelphia. 2001; 465.

[7] Kimura K, Reinhardt TA, Goff JP. Parturition and hypocalcaemia blunt calcium signals in immune cells of dairy cattle. J. Dairy Sci 2006; 89: 258895. https://doi.org/10.3168/jds.S0022-0302(06)72335-9

[8] Mokhber Dezfouli M, Eftekhari Z, Sadeghian S, Bahounar A, Jeloudari M. Evaluation of hematological and biochemical profiles in dairy cows with left displacement of the abomasum. Comp Clin Path 2013; 22 : 175-179. https://doi.org/10.1007/s00580-011-1382-5

[9] Bolton JR, Pass DA. The alimentary tract. Clinicopathologic principles for veterinary medicine. W. F. Robinson and C. R. R. Huxtable. Cambridge, Cambridge University Press 1988; 99-121. https://doi.org/10.1017/СBO9780511565304

[10] Radostits OM, Gay CC, Blood DC, Hinchcliff KW. Veterinary Medicine. Wiley \& Sons, New York. 2000.

[11] Constable PD, Done H S, Hincheliff KW, Grunberg W. Veterinary Medicine. A text book of diseases in cattle, horses, sheep, pigs and goats. Elisevier Ltd. 11th Ed. 2017.

[12] Poulton PJ, Vizard AL, Andersonb GA, Pyman MF. Importance of secondary damage in downer cows. Aust. Vet. J 2016; 94: 138-144. https://doi.org/10.1111/avj.12437

[13] Cox VS, Marsh WE, Gerald RS, Thomas FF, John SO. Downer Cow Occurrence in Minnesota Dairy Herds. Prev. Vet. Med. 1986; 4: 249-260. https://doi.org/10.1016/0167-5877(86)90027-9

[14] Abuom TO, Njenga MJ, Wabacha JK, Tsuma VT, Gitau GK. Incidence and risk factors of periparturient conditions in smallholder dairy cattle herds in Kikuyu Division of Kiambu District, Kenya. Ethiop Vet J 2012; 16: 85102. https://doi.org/10.4314/evj.v16i2.8

[15] Rulff R, Schrödl W, Basiouni S, Krüger M. Biochemical investigations and glyphosate detection in downer cow syndrome. IJSER 2016; 7: 15481553.

[16] Duraj J, Ceroni V. Changes in Haematobiochemical Indicators as Prognosis Criteria for Cows Affected by the "Downer" Syndrome. Anglisticum Journal (IJLLIS) 2017; 6: $84-90$. https://doi.org/10.0001/ijllis.v6i12.1601

[17] Van Metre DC, Callan RJ, Garry FB. Downer cows: diagnosis and assessment. In: Proceedings of the Australian Cattle Veterinarians Conference, Melbourne, 2001; 14-21.

[18] Shpiegel NY, Avidar Y, and Bogin E. Value of measurements of the serum activities of creatine phosphokinase, aspartate aminotransferase and lactate dehydrogenase for predicting whether recumbent dairy cows will recover. The Veterinary Record 2003; 152(25): 773-776. https://doi.org/10.1136/vr.152.25.773

[19] Barrington GM. Parturient paresis in cows. In Aiello, S. Ed. The Merck veterinary manual. 8th ed., Merck and Co. Inc., Whitehouse Station, New Jersey, USA., 1998; 739-741.

[20] Kojouri G, Hedayati FS, Zandi S, Karimzadeh J, et al. The Degrees of parturient hypocalcemia and its relevance to other metabolic profile parameters in downer cows. IJRHR 2016; 1, 1-8. https://doi.org/10.22055/IJRHR.2017.12841

[21] Labonte J, Dubuc J, Roy JP, Buczinski S. Prognostic value of cardiac troponin I and lactate in blood of dairy cows affected by downer cow syndrome. J Vet Intern Med 2018; 32, 484-490. https://doi.org/10.1111/jvim.14874

[22] Kachhawaha S, Tanwar RK. Biochemical and enzymatic changes in downer cow syndrome. Indian J Anim Sci 2010; 80 (4): 338-339.

[23] Wubishet F, Dechassa T, Nejash A, Wahid MA. Milk Fever and its Economic Consequences in Dairy Cows: A Review, Global Veterinaria 2016; 16 : 441-452. https://doi.org/10.5829/idosi.gv.2016.16.05.103137

[24] Jensen KC, Frömke C, Schneider B, et al. Case-control study on factors associated with a decreased milk yield and a depressed health status of dairy herds in northern Germany. BMC Vet Res 2019; 15: 442. https://doi.org/10.1186/s12917-019-2190-4

[25] Divers TJ, Peek SF. Rebhun's diseases of dairy cattle, 2nd Ed. Elsevier Health Sciences, UK. 2008.

[26] Colakoglu HE, Yazlik MO, Pekcan M, Kaya U, Kacar C, Vural MR, Kurt S, Yildirim MM, Bas A, Kuplulu S. Impact of prepartum body condition score loss on metabolic status during the transition period and subsequent fertility in Brown Swiss dairy cows. J Vet Res 2019; 63: 375-382. https://doi.org/10.2478/jvetres-2019-0039
[27] Bewley JM, Schutz MM. An interdisciplinary review of body condition scoring for dairy cattle. Prof. Anim. Sci. j 2008; 24: 507-529. https://doi.org/10.15232/S1080-7446(15)30901-3

[28] Busato A, Faissle D, Kupfer U, Blum J. Body Condition Scores in Dairy Cows: Associations with Metabolic and Endocrine Changes in Healthy Dairy Cows. J Vet Med A Physiol Pathol Clin Med 2002; A 49(9):455-60. https://doi.org/10.1046/j.1439-0442.2002.00476.x

[29] Bicalho RC, Vokey F, Erb HN, Guard CL. Visual locomotion scoring in the first seventy days in milk: Impact on pregnancy and survival. J. Dairy Sci 2007b; 90: 4586-4591. https://doi.org/10.3168/jds.2007-0297 [30] Piccione G, Messina V, Marafioti S, Casella S, Giannetto C, Fazio F. Changes of some haematochemical parameters in dairy cows during late gestation, postpartum, lactation and dry periods. Vet. Med. Zoot 2012; 58: 59-64.

[31] Correa MT, Erb HN, Scarlett JM. Risk factors for downer cow syndrome. J. Dairy Sci. 1993; 76 (11): 3460-63. https://doi.org/10.3168/jds.S00220302(93)77685-7

[32] Goff JP. The monitoring, prevention, and treatment of milk fever and subclinical hypocalcemia in dairy cows. Vet J 2008; 176, 50-57. https://doi.org/10.1016/j.tvjl.2007.12.020 